The genome sequence of the avian vampire fly (Philornis downsi), an invasive nest parasite of Darwin's finches in Galápagos

Melia Romine ${ }^{1}$, Sarah A. Knutie ${ }^{2,3}$, Carly M. Crow ${ }^{4}$, Grace J. Vaziri², Jaime Chaves ${ }^{5,6}$,

$7 \quad{ }^{1}$ School of Biomedical Sciences, Kent State University, Kent, OH, USA

$8 \quad{ }^{2}$ Department of Ecology and Evolutionary Biology, University of Connecticut, Storrs, CT USA

$9 \quad{ }^{3}$ Institute for Systems Genomics, University of Connecticut, Storrs, CT USA

$10{ }^{4}$ Department of Biological Sciences, Northern Illinois University, DeKalb, IL, USA

$11{ }^{5}$ Department of Biology, San Francisco State University, San Francisco, CA, USA

$12{ }^{6}$ Colegio de Ciencias Biológicas y Ambientales, Universidad San Francisco de Quito, Quito,

13 Ecuador

$14{ }^{7}$ Department of Biological Sciences, Kent State University, Kent, OH, USA

$16 *$ co-senior authors

$17 \quad{ }^{*}$ corresponding author (slamichh@kent.edu $)$ 
Abstract

21 The invasive avian vampire fly (Philornis downsi) is considered one of the greatest threats to the

22 unique and endemic avifauna of the Galápagos Islands, Ecuador. The fly parasitizes nearly every

23 passerine species, including Darwin's finches, in the Galápagos. The fly is thought to have been

24 introduced from mainland Ecuador, although the full pathway of invasion is not yet known. The

25 majority of research to date has focused on the effects of the fly on the fitness of avian hosts and

26 explorations of mitigation methods. A lag in research related to the genetics of this invasion

27 demonstrates, in part, a need to develop full-scale genomic resources with which to address further

28 questions within this system. In this study, an adult $P$. downsi collected from San Cristobal Island

29 within the Galápagos archipelago was sequenced to generate a high-quality genome assembly. We

30 examined various features of the genome (e.g., coding regions, non-coding transposable elements)

31 and carried out comparative genomics analysis against other dipteran genomes. We identified lists

32 of gene families that are significantly expanding/contracting in $P$. downsi that are related to

33 insecticide resistance, detoxification, and potential feeding ecology and counter defense against

34 host immune responses. The $P$. downsi genome assembly provides an important foundational

35 resource for studying the molecular basis of its successful invasion in the Galápagos and the

36 dynamics of its population across multiple islands. The findings of significantly changing gene

37 families associated with insecticide resistance and immune responses highlight the need for further

38 investigations into the role of different gene families in aiding the fly's successful invasion.

39 Furthermore, this genomic resource will also better help inform future research studies and

40 mitigation strategies aimed at minimizing the fly’s impact on the birds of the Galápagos.

42 Keywords: Avian vampire fly genome, parasitic invasion, Galápagos, insecticide resistance,

\section{Darwin's finches}




\section{Introduction}

The invasive avian vampire fly (Philornis downsi) (Figure 1a) is considered among the greatest threats to the unique and endemic avifauna of the Galápagos Islands, Ecuador (Causton et al., 2013). The fly parasitizes eleven species of Darwin's finches (Figure 1b) as well as nearly every other Galápagos passerine species (Causton et al., 2013; Fessl et al., 2018). The earliest record of adult flies from the Galápagos occurred in 1964, but the fly was not observed in the nests of birds until 1997 (Fessl and Tebbich, 2002; Causton et al., 2006). The fly has now been

56 (Causton et al., 2013). The impact of parasitism by the fly has been severe in some populations

57 of birds in Galápagos and while the effects are variable, some studies have reported near-total

58 nest failure rates due to parasitism (Dudaniec et al., 2007; Koop et al., 2011; Koop, Le Bohec, et al., 2013; O’Connor et al., 2014; Knutie et al., 2016a; Heimpel et al., 2017; Addesso et al.,

60 2020). The fly has also been implicated in the decline of the medium tree finch (Camarhyncus

61 pauper), the warbler finch (Certhidia olivacea), and the mangrove finch (Camarhyncus

62 heliobates) (Dvorak et al., 2004; Grant et al., 2005; Cunninghame et al., 2017; Peters and

63 Kleindorfer, 2018; Bulgarella et al., 2019). Furthermore, the potential for population-level

64 declines of even relatively prominent bird species, e.g., the medium ground finch, have also been 65 demonstrated using predictive models (Koop et al., 2015).

The genus Philornis includes approximately 50 species found primarily in the Neotropics and

67 into North America (Dodge, 1955, 1963; Spalding et al., 2002; Dudaniec and Kleindorfer, 2006;

68 Couri et al., 2007). Of the described species within Philornis, only two species (including $P$.

69 downsi) are free-living ectoparasites within the nests of their hosts (Fessl et al., 2006), while

70 most others are subcutaneous on their hosts. Several Philornis species are found in mainland 
71 Ecuador (Bulgarella et al., 2015, 2017), but $P$. downsi remains the only recorded species of the

72 genus present, to date, in the Galápagos. $P$. downsi is thought to have been introduced from

73 mainland Ecuador, though the full pathway of invasion is not yet known (Fessl et al., 2018).

74 Preliminary population genetics studies show that flies within the archipelago have a high degree

75 of relatedness relative to those on the mainland, which supports the hypothesis of a relatively

76 recent invasion and also the possibility of continued gene flow between populations in the

77 Galápagos (Dudaniec et al., 2008; Koop et al., 2021).

A collaborative research effort has been made to continue monitoring the effects of the avian

vampire fly on bird populations in the Galápagos. These efforts aim to identify source

population(s), the pathway and mechanism of invasion, and possible long-term mitigation

81 methods, including the Sterile Insect Technique and biocontrol (Causton et al., 2013, 2019).

82 Current stopgap mitigation efforts in the Galápagos include the direct application of insecticide

83 to bird nests. Newly hatched nestlings are removed, and a permethrin solution is sprayed inside

84 the nest and allowed to dry, at which point the nestlings are placed back in the nest. This method

85 has been shown to effectively reduce parasites in the nest and increase fledging success (Koop et

86 al., 2011). A continuation of this method relies on birds incorporating permethrin-treated cotton

87 into their nests, achieving similar increases in fledging success (Knutie et al., 2014). Both

88 methods, with subtle variations, are being used in attempts to increase the nesting success of the

89 critically endangered mangrove finch, currently one of the most endangered birds in the world

90 (Fessl et al., 2018). The same method is also being used successfully to protect endangered bird

91 species against their respective parasites in Australia (Alves et al., 2020).

92 Despite the robust number of studies that explored the effects of these flies on hosts in the

93 Galápagos, questions remain about the underlying ecological and evolutionary mechanisms of 
94 their successful invasion in the Galápagos. This knowledge gap demonstrates the need to develop

95 a full-scale genomic resource of the fly as it provides a critical knowledge base from which to

96 explore these questions, similar to other parasites of concern (Scott et al., 2020). In this study,

97 we generated a high-quality draft genome of the avian vampire fly, which is expected to become

98 an important resource of future molecular studies in this system. We further carried out

99 comparative genomics analysis with additional published dipteran genomes that identified

100 evidence of significantly changing gene families associated with insecticide resistance,

101 detoxification, and possible counter defense against host immune responses. These results serve

102 as the first step toward investigations of this fly's ability to rapidly evolve traits associated with

103 its successful invasion in the Galápagos. From an applied aspect, these genomic resources will

104 also help inform future research studies and mitigation strategies aimed at minimizing the fly's

105 impact on the birds of the Galápagos.

106

107 Materials and Methods

108 Sampling and DNA extraction for genome sequencing

109 Flies were collected in Jardín de las Opuntias on San Cristobal Island, Galápagos,

110 Ecuador $\left(-0.9491651^{\circ},-89.5528454^{\circ}\right)$ in March-April of 2019. Adult flies were reared from

111 pupae collected in the nests of small ground finches (Geospiza fuliginosa). When the nests were

112 empty because nestlings died or fledged, all larvae and pupae were extracted from the nest and

113 placed in a falcon tube with a modified lid that allowed airflow. After flies eclosed from their

114 pupal case, they were placed in the freezer, then preserved in 95\% ethanol. Preserved flies were

115 transported to the University of Connecticut, then shipped to Northern Illinois University for

116 further processing. DNA was extracted using DNeasy Blood and Tissue Kit (Qiagen, Valencia, 
117 California, USA) on whole fly samples after wings and legs were removed using forceps. All

118 samples were treated with Monarch ${ }^{\circledR}$ RNase A (New England Biolabs) to remove RNA from

119 genomic DNA samples. Multiple samples were extracted and those with low yields of DNA or

120 contamination were discarded from further processing. Quantification of double-stranded DNA

121 was done using QuBit ${ }^{2}$ and samples were run on a gel to assess fragmentation.

123 Estimate of genome size and ploidy

We prepared a 10X Chromium GEM library from the extracted DNA above according to

125 the manufacturer's recommended protocols. The library was sequenced using the Illumina $10 \mathrm{X}$

126 platform to generate paired-end $150 \mathrm{bp}$ reads. We used a k-mer based approach to estimate

127 genome size, heterozygosity, and repeat content from unprocessed short sequencing reads

128 (Vurture et al., 2017). We also used the k-mer distribution to extract heterozygous k-mer pairs to

129 assess the ploidy level in P. downsi (Ranallo-Benavidez et al., 2020). These estimates of genome

130 size and ploidy were then used to choose parameters for the downstream genome assembly

131 pipeline.

132

133 Genome assembly and annotation

134 The 10x Chromium linked reads generated above were used to generate a reference

135 genome using Supernova.v.2.1.1 (Weisenfeld et al., 2017) with default parameters. The genome

136 contiguity statistics such as scaffold $\mathrm{N}_{50}$ and the total number of scaffolds etc. were calculated

137 using custom Perl scripts. We further compared the draft genome assembly against a set of

138 conserved genes in Diptera using BUSCO (Waterhouse et al., 2017) to assess gene-space

139 completeness. We also mapped the short sequencing reads back to the draft genome assembly 
140 using BWA (Li and Durbin, 2009) to estimate how many short-sequence reads were used to

141 build the reference genome and infer genome completeness. The annotation of the $P$. downsi

142 genome was done using the MAKER annotation pipeline (Cantarel et al., 2008). We combined

143 protein homology evidence (using publicly available protein datasets from major dipteran

144 lineages, downloaded from the Ensemble database (Cunningham et al., 2019) and ab-initio gene

145 predictions models to annotate the genome.

147 Transposable elements (TE) in $P$. downsi

148 We combined homology-based and de novo approaches using Repeatmasker (Smit

149 Hubley P., 2013; Flynn et al., 2019) to characterize TEs in P. downsi. We used two different sets

150 of repeat libraries, (a) reference repeat library downloaded from the Repbase database (Bao et

151 al., 2015) and (b) de novo custom-built species-specific repeat library generated for P. downsi

152 using RepeatModeler (Flynn et al., 2019). The usage of the de novo species-specific repeat

153 library increased the accuracy of detection and annotation of transposable elements. For an

154 unbiased comparison of repeat landscapes among all species, we used similar approaches to

155 detect TEs in the Housefly (M. domestica), Stable fly (S. calcitrans), Tsetse fly (G. morsitans),

156 Mediterranean fruit fly (C. capitata), Fruit fly (D. melanogaster) and Yellow fever mosquito (A.

157 aegypti), together with an outgroup, Postman butterfly (H. melpomene).

159 Orthologs to other dipteran genomes

160 We inferred orthogroups and orthologs by comparative analysis of proteomes in $P$.

161 downsi and six additional dipteran species (M. domestica, S. calcitrans, G. morsitans, C.

162 capitata, D. melanogaster, and A. aegypti), together with an outgroup, $H$ melpomene. This 
163 analysis used the draft proteome of $P$. downsi generated from our genome annotation pipeline

164 described above. Complete proteomes of each of the remaining six species were downloaded

165 from the Ensemble database (Cunningham et al., 2019). The orthologs inference was carried out

166 using Orthofinder (Emms and Kelly, 2015).

168 Gene family evolution

To explore the evolution of gene families in $P$. downsi to other Dipterans, we first

170 constructed a maximum likelihood phylogeny using 3,070 single-copy orthologs among these

171 eight species used for inferring orthologues (Figure 3a). We then used this phylogeny to analyze

172 the changes in gene family size across lineages leading to each of these eight species using a

173 maximum likelihood approach (CAFÉ) (De Bie et al., 2006) that uses a birth and death process

174 to model gene gain and loss across a phylogenetic tree.

175

176 Results

\section{Genome sequencing and assembly}

178 We sampled an adult P. downsi fly in Jardín de las Opuntias on San Cristobal Island,

179 Galápagos. DNA library was prepared using 10X Chromium linked-read approach (Zheng et al.,

180 2016) and sequenced using Illumina 10X platform to generate paired-end $150 \mathrm{bp}$ reads which

181 resulted in $\sim 479$ million read pairs ( $\sim 72 \mathrm{~Gb}$ of raw sequence data). We first generated a k-mer

182 distribution based on these short-sequencing reads for preliminary characterization of genome

183 structure in P. downsi (e.g., genome size, an abundance of repetitive elements, rate of

184 heterozygosity) (Supplementary Table 1, Supplementary Figure 1) that further allowed us to

185 make informed decisions on parameters needed for building a reference genome. We also 
utilized the k-mer distribution to estimate the ploidy level in P. downsi, which indicated it to be a diploid species (Supplementary Figure 2).

Based on genome size estimates using k-mer distributions from short sequence reads

189 (Supplementary Table 1), we had $\sim 91 \mathrm{X}$ sequence coverage for generating the draft de-novo

190 genome assembly. The total estimated length of the draft assembly was 971.6 Mb. The assembly

191 contained 41,176 total scaffolds (minimum $1000 \mathrm{bp}$ to maximum $8.6 \mathrm{Mb}$ ) with scaffold $\mathrm{N}_{50}$ of

$192 \quad 1.3 \mathrm{Mb}$. We further assessed genome contiguity and gene-space completeness using

193 benchmarking universal single-copy orthologs (BUSCO) (Waterhouse et al., 2017). Among

194 3,258 genes highly conserved across Diptera, 3,147 (95.8\%) full-length genes were detected in

195 the $P$. downsi draft genome assembly. Partial sequences of 71 genes were identified (2.2\%) and

196 only $67(2.0 \%)$ were missing, indicating a high degree of contiguity in the $P$. downsi genome. In

197 addition, $99.16 \%$ of total short sequencing reads aligned back to the draft genome indicating a

198 high degree of genome completeness as well.

\section{Genome annotation}

We combined protein homology-based evidence and ab-initio gene prediction models

202 using the MAKER genome annotation pipeline (Cantarel et al., 2008) which identified 15,774

203 protein-coding genes in the $P$. downsi genome. We compared the genome annotation of $P$.

204 downsi with two other published and highly curated dipteran genomes, Musca domestica (Scott

205 et al., 2014) and D. melanogaster (Adams et al., 2000). We annotated fewer genes in the $P$.

206 downsi genome $(15,774)$ compared to that of $M$. domestica $(17,283)$ or D. melanogaster $(17,468)$

207 (Table 1). The average length of genes is similar among $P$. downsi and D. melanogaster, whereas 
M. domestica typically has longer genes. The mean number of exons per gene is fewer in $P$. downsi compared to the other two species.

Table 1: Statistics of genomic features among three fly genomes

\begin{tabular}{|c|c|c|c|}
\hline Genome statistics & P. downsi & $\begin{array}{c}\text { M. domestica } \\
\text { (Scott et al. 2014) }\end{array}$ & $\begin{array}{c}\text { D. melanogaster } \\
\text { (Adams et al. 2000) }\end{array}$ \\
\hline Genome size $(\mathrm{Gb})$ & 0.97 & 0.69 & 0.18 \\
\hline Total genes & 15,774 & 17,283 & 17,468 \\
\hline Avg. gene length (bp) & 4,789 & 13,747 & 5,830 \\
\hline Total exons & 56,595 & 123,831 & 188,405 \\
\hline Avg. exon length (bp) & 367 & 453 & 485 \\
\hline Number of Exons per gene & 3.59 & 7.16 & 10.79 \\
\hline
\end{tabular}

214 determinants of genome size variation (Kapusta et al., 2017; Lamichhaney et al., 2021), and

215 important contributors to the evolutionary potential of an organism (Pourrajab and

216 Hekmatimoghaddam, 2021). We characterized the transposable elements in the $P$. downsi

217 genome using homology-based (Smit Hubley P., 2013) and de-novo approaches (Flynn et al.,

218 2019). More than half of the genome (51.7\%) of $P$. downsi consists of transposable elements

219 (Supplementary Table 2). Among these sequences, 9.3\% of the genome are retroelements $(7.7 \%$

220 LINEs and 1.6\% LTRs) and 23.4\% DNA transposons. Short interspersed nuclear elements

221 (SINEs), a major category of retroelements, were not detected in the P. downsi genome.

223 several other species including the house fly (Musca domestica), stable fly (Stomoxys calcitrans),

224 tsetse fly (Glossina morsitans), Mediterranean fruit fly (Ceratitis capitata), fruit fly (Drosophila

225 melanogaster) and yellow fever mosquito (Aedes aegypti). The postman butterfly (Heliconius

226 melpomene) was used as an outgroup. Transposable elements are known to be highly correlated 
227 with genome size across the tree of life (Kidwell, 2002; Lynch, 2007), and our results across

228 various dipteran genomes are consistent with this pattern (Figure 2a).

229 We also compared different categories of transposable elements across these seven

230 genomes (Figure 2b). P. downsi had the highest proportion of DNA transposons (23.4\%) among

231 all taxa analyzed. In comparison, only $6.36 \%$ of the $S$. calcitrans genome and $15.96 \%$ of the $M$.

232 domestica genome consisted of DNA transposons. Although P. downsi and S. calcitrans have

233 similar genome sizes, S. calcitrans had slightly higher amounts of repeat content in its genome

234 (58.3\%), compared to P. downsi (51.7\%) (Figure 2b). S. calcitrans had higher amounts of long

235 interspersed nuclear elements (LINEs) (23.8\%), compared to P. downsi (7.7\%). We observed

236 that most Diptera (except Aedes) have only a few SINE elements, one of the major classes of

237 transposable elements (Figure 2b). LTR elements were relatively common in D. melanogaster,

238 whereas other dipterans had a low amount of LTR elements (including P. downsi).

Orthologs to other dipteran genomes and outgroup Heliconius

Comparative genomics analysis of 113,047 protein sequences from $P$. downsi and seven

242 other species (listed above) identified 11,112 orthogroups. A total of 95,567 proteins (out of

$243113,047,86.3 \%$ ) were assigned to these orthogroups. The mean size of an orthogroup was 8.8

244 genes/species, and 3,069 orthogroups had singly copy genes in each species. A total of 5,754

245 orthogroups were shared among all eight species. Only a few orthogroups (minimum 496 in $A$.

246 aegypti and a maximum of 1,445 in M. domestica) were present in fewer than four species

247 (Figure 3a). The number of unique orthologs in each species was consistent with their

248 phylogenetic relationships (e.g., A. aegypti and the outgroup H. melpomene had the highest

249 number of unique orthogroups). The number of shared orthologs among each pair of species is 
250 presented in Supplementary Table 3. The number of orthologs identified in $P$. downsi is

251 consistent with other published dipteran genomes (Figure 3a, Supplementary Table 3), indicating

252 no major bias in the genome assembly and annotation pipeline used in this study.

Within P. downsi, 13,706 out of 15,774 (86.9\%) annotated genes were assigned to

254 orthogroups. We expect the remaining missing genes to either be the most recently evolved

255 orphan genes in the branch leading to the $P$. downsi lineage or the consequence of a lack of

256 inclusion of enough closely related species of $P$. downsi in the analysis. The distribution of these

257 unique genes in the $P$. downsi genome is random and does not show specific clustering patterns

258 across various locations of the genome.

259 We also compared the number of pairwise orthogroups that are uniquely shared among

260 all eight species (Figure 3b). A total of 993 orthogroups were unique to Diptera (after excluding

261 the outlier H. melpomene), 79 orthogroups were shared only between $M$. domestica and $P$.

262 downsi and 12 putative gene families were unique to only $P$. downsi. These 12 gene families

263 consisted of 27 genes and the great majority had the best BLAST hits against "uncharacterized"

264 or "hypothetical" proteins in other related species (Supplementary Table 4). This result indicates

265 that these gene families that appeared "unique" in $P$. downsi are likely due to the lack of proper

266 gene annotation in other species.

267 We further examined the gene ontology terms of the 993 orthogroups unique to Diptera

268 using the PANTHER gene ontology database (Mi et al., 2021). The common biological

269 processes of these genes included localization, locomotion, immune system processes, response

270 to stimulus, and reproduction (Supplementary Figure 3), many of which are likely key genes for

271 the overall development and function of dipterans. 


\section{Gene family evolution}

We used a maximum likelihood approach to analyze changes in gene family size among

275 the same eight species used for inferring orthologs (De Bie et al., 2006). This method uses a

276 statistical approach to model gene gain and loss, accounting for phylogenetic history and assess

277 the significance of the observed gene family size differences among taxa. Across 11,112

278 orthogroups we identified before among eight taxa; 101 gene families were significantly

279 expanding/contracting $(\mathrm{p}<0.01)$ across the phylogenetic tree. 25 out of these 101 gene families

280 were identified in the branch leading to $P$. downsi. The list of these gene families in $P$. downsi

281 included those associated with insecticide resistance or detoxification and host defense or

282 immunity proteins (Table 2).

284 Table 2: List of significantly expanding/contracting $(\mathrm{p}<0.01)$ gene families in P. downsi

\begin{tabular}{|l|l|}
\hline Functional Categories & Gene Family \\
\hline Insecticide Resistance and Detoxification & Cytochrome P450 \\
\hline & Glutathione S Transferase \\
\hline Defense against host Immunity & Cuticular Protein \\
\hline & Fibrinogen C-terminal Domain-Containing Protein \\
\hline & Scp Domain-Containing Protein \\
\hline
\end{tabular}

286 Gene families associated with insecticide resistance and detoxification

287 Cytochrome P450 gene family

We examined the number of genes in the cytochrome P450 (CYP450) family across the

289 seven Diptera and the H. melpomene outgroup. P. downsi and M. domestica have an expanded

290 CYP450 gene family in comparison to their most recent common ancestor with G. morsitans

291 (family Glossinidae) (Figure 4a). For example, The P. downsi CYP450 family is composed of

292102 genes in comparison to 66 in G. morsitans. An even greater level of expansion was observed

293 in two other members of Muscidae (M. domestica: 143 genes and S. calcitrans: 193 genes). 
294 Compared to G. morsitans, the expansion of CYP450 genes is mainly found in CYP4, CYP6,

295 and CYP28 genes (Figure 4b). The CYP6 subfamily in P. downsi is composed of 25 genes,

296 almost doubling the number from the 14 genes present in G. morsitans. We also found an

297 expansion in the CYP4 subfamily from 15 genes in G. morsitans to 31 genes in P. downsi. A

298 similar expansion was seen in the CYP28 subfamily (4 genes in $G$. morsitans to 8 genes in $P$.

299 downsi).

300

301 Glutathione S-transferase gene family

302 The P. downsi Glutathione S-transferase family consists of 25 genes and the pattern

303 across the dipterans is similar to observations of the Cytochrome P450 gene family expansion

304 (Figure 4c). For example, in comparison to G. morsitans (15 genes), P. downsi and M. domestica

305 have an expanded number of genes (25 genes in P. downsi, 31 genes in M. domestica). The

306 GSTs are grouped into six subclasses (Delta, Epsilon, Omega, Sigma, Theta, and Zeta). The

307 expansion of GSTs in P. downsi occurred mainly in the Delta, Epsilon, and Zeta subclasses

308 (Figure 4d).

310 Cuticular Protein

311 The P. downsi cuticular gene family consists of 214 genes and the pattern across the

312 dipterans is similar to observations of the Cytochrome P450 and GST gene family expansions

313 (Supplementary Figure 4). For example, the Muscidae family (represented here by P. downsi, M.

314 domestica, and $S$. calcitrans) has an expanded gene family in comparison to their most recent

315 common ancestor with G. morsitans (115 genes). An even greater level of expansion was 
316 observed by two other members of Muscidae (M. domestica - 357 genes and S. calcitrans -270

317 genes).

319 Gene families associated with immunity

Two gene families (Fibrinogen C-terminal Domain-Containing Protein and Scp Domain-

321 Containing Protein) associated with immunity were also identified as significantly changing in P.

322 downsi (Table 2). Opposite of genes associated with insecticide resistance and detoxification

323 (Cytochrome P450 and Glutathione S-transferase), these gene families showed a reduction in the

324 number of genes in P. downsi compared to the most recent common ancestor with G. morsitans

325 (Supplementary Table 5). They also show contraction in comparison with two included members

326 of the Family Muscidae (M. domestica and S. calcitrans).

\section{Discussion}

In this study, we report the first genome sequence of the avian vampire fly, a highly

330 invasive parasitic nest fly that threatens endemic avifauna of the Galápagos Islands (Fessl et al.,

331 2018; Causton et al., 2019). This genome is meant to serve as an important resource to research

332 efforts aimed at characterizing the molecular mechanisms of the fly's successful invasion in the

333 Galápagos. The genome size of $P$. downsi is $971.6 \mathrm{Mb}$ and its high quality is reflected both in

334 terms of genome contiguity (scaffold $\mathrm{N}_{50}$ of $1.3 \mathrm{Mb}$ ) and completeness $(98 \%$ BUSCO gene-space

335 score). Interestingly, the total number of annotated genes in $P$. downsi is slightly lower compared

336 to other published fly genomes (M. domestica and D. melanogaster) (Table 1). The low gene

337 count likely reflects the lack of $P$. downsi specific transcriptome data in this study, which

338 perhaps led to reduced gene predictions. We aim to improve the $P$. downsi genome annotations 
339 in the future using additional transcriptomic resources using additional flies collected from the

340 Galápagos.

341 Transposable elements (TE) are typically non-coding sequences that can insert themselves in

342 various places of the genome, often with neutral or deleterious phenotypic consequences

343 (Bourque et al., 2018). The role of TEs, as well as their evolution across insect genomes, is still

344 an area of major research, but they are thought to be important drivers of genomic architecture

345 depending on the location of the genome to which they insert themselves (i.e., coding versus

346 non-coding regions). Furthermore, TE may also be a critical mechanism of adaptive evolution, as

347 has been shown in an invasive ant species (Schrader et al., 2014). Analysis of transposable

348 elements in $P$. downsi and across other dipteran genomes showed a strong positive correlation

349 between genome size and repeat content (Figure 2a), consistent with similar findings across other

350 taxa (Lynch, 2007; Lamichhaney et al., 2021). Interestingly, P. downsi had a higher number of

351 DNA transposons (Class II TEs) than any other compared genome, including M. domestica, $S$.

352 calcitrans, and G. morsitans. While long terminal repeat (LTR) transposons, LINEs, and SINEs)

353 were present in the species studied, $P$. downsi had no SINEs, a finding consistent with a study by

354 Petersen and colleagues (Petersen et al., 2019) showing that SINEs contribute less than $1 \%$ to the

355 TE content of dipterans. However, it is important to note that some SINEs may be present in $P$.

356 downsi but are currently masked as unclassified. Future research should explore the role of TEs,

357 especially DNA transposons, in aiding the invasion of $P$. downsi to the Galápagos.

358 Comparative genomics analysis of $P$. downsi and other additional dipteran genomes

359 allowed us to identify gene families that were significantly expanded/contracted $(\mathrm{p}<0.01)$ in $P$.

360 downsi. The list of these gene families in P. downsi included those associated with insecticide

361 resistance or detoxification and host defense or immunity proteins, and we predict that these 
gene families are associated with a successful invasion of $P$. downsi in the Galápagos (Table 1).

363 E.g. CYP450 mono-oxygenases are a diverse superfamily of proteins, including enzymes,

364 associated with catabolism and anabolism of xenobiotics and endogenous compounds. These

365 monooxygenase-mediated metabolisms have allowed numerous insect species to develop

366 insecticide resistance and detoxification (Scott, 1999; Wen et al., 2011). The expansion of

367 CYP450 genes in P. downsi is mainly found in CYP4 and CYP6 gene subfamilies (Figure 4b),

368 which has also been shown in other species from the family Muscidae (Scott et al., 2014;

369 Olafson et al., 2021). Interestingly, in higher Diptera, many of the genes within the CYP6

370 subfamily (e.g., CYP6A, CYP6G, CYP6D) are associated with insecticide resistance

371 (Feyereisen, 2012). For example, the Cyp6g1 gene is involved in resistance to the insecticide

372 Dichlorodiphenyltrichloroethane (DDT) in D. melanogaster (Festucci-Buselli et al., 2005). The

373 CYP4 subfamily can also influence the breakdown of synthetic insecticides (Iga and Kataoka,

374 2012). Cyp4d4v2, Cyp4g2, and Cyp6a38 can be co-up-regulated in-house flies that are resistant

375 to the insecticide permethrin, which is used to control P. downsi in the Galapagos (Zhu et al.,

376 2008). Overall, the expansion of CYP4 and CYP6 subfamilies may indicate the evolution of

377 insecticide resistance in P. downsi over macroevolutionary time (i.e., before arriving in the

378 Galápagos), which could have facilitated its invasion to the Galápagos and might affect its

379 management on the islands.

380 Glutathione S-transferase (GSTs) was another major expanding gene family in P. downsi.

381 GSTs are a highly conserved, large family of dimeric enzymes associated with detoxification of

382 endogenous and/or xenobiotic compounds, such as insecticides (Ketterman et al., 2011). The

383 GST family is further grouped into six subclasses (Delta, Epsilon, Omega, Sigma, Theta, and

384 Zeta), with Delta and Epsilon being specific subclasses found in the class Insecta. We observed 
an expansion of GST genes in P. downsi relative to G. morsitans, but fewer than were found in M. domestica and S. calcitrans. The major expansions of the GST family in P. downsi were observed in Delta and Epsilon subclasses (Figure 4d). Insecticides, such as permethrin, are used to experimentally manipulate $P$. downsi abundance in bird nests to study the effects of the parasite on the health of the birds (Fessl et al., 2010; Koop et al., 2011; Koop, Le Bohec, et al., 2013; Koop, Owen, et al., 2013; Knutie et al., 2014, 2016b; O’Connor et al., 2014; McNew et al., 2020; Addesso et al., 2020). Increased expression of GSTs following permethrin exposure has been documented in several insect species including oriental fruit flies (Bactrocera dorsalis) (Hu et al., 2008). Expansion of the GST gene family in $P$. downsi may be a result of such

394 permethrin exposure. However, gene expression studies that further explore the role of the GST 395 gene family in insecticide resistance and detoxification are needed across insect taxa including $P$. downsi. It is important to note that the expansion of CYP450 and GST families observed in $P$.

397 downsi may be an artifact of phylogenetic relationships rather than ecological adaptations. Still, 398 given the observed and predicted impacts of $P$. downsi on native endemic host populations, it is 399 important to consider the implications of expanded gene families related to detoxification and 400 insecticide resistance. responses to parasitism (Koop, Owen, et al., 2013). This response is most prominent in adult 403 females that are likely parasitized while brooding nestlings or eggs on the nest. However, little is 404 known about the ability of host bird immunological responses to effectively reduce fly fitness, in 405 part, because so little is known about the fly itself. One of the most prominent questions is 406 whether the $P$. downsi possesses the ability to counter defend against host immune responses. 407 We identified a reduction in the size of two additional gene families (Fibrinogen C-terminal 
408 Domain-Containing and SCP domain-containing gene family), both with immune function

409 properties in P.downsi (Table 1, Supplementary Table 5). Fibrinogen plays a key role in blood

410 clot formation through the conversion of fibrinogen to insoluble fibrin (Weisel and Litvinov,

411 2017) and the C-terminal domain of fibrinogen is the primary binding site of platelets

412 (Hanington and Zhang, 2011). The Sperm-coating glycoprotein (Scp) family contains, among

413 other proteins, antigen 5 (Ag5), which is associated with the venom secretory ducts of stinging

414 insects (Gibbs et al., 2008). However, the interpretation of these results is difficult without

415 further investigation into whether these genes are associated with innate immune responses of $P$.

416 downsi toward their hosts or whether they might be important components of their feeding

417 ecology. The goal of our study was not to make such inferences, but rather to highlight

418 promising avenues of future research.

419 The invasion of $P$. downsi has had dramatic negative effects on the endemic avifauna of

420 the Galápagos, including Darwin's finches. As researchers work to better understand the

421 pathway of invasion and the ecological and evolutionary processes that may have facilitated its

422 invasion to the Galápagos, the need for a high-quality whole genome sequence has grown. The

423 addition of this resource is therefore meant to provide the foundation for further investigations

424 using genomics tools in this system. These genomic resources will further allow us to understand

425 the evolution of the $P$. downsi defense in response to host defenses or disease resistance itself.

426 Gene expression studies could shed light on the development of larvae and at what stage they are

427 most vulnerable to host defenses. Further population-scale resequencing of various populations

428 of $P$. downsi will also allow us to explore mechanisms of local adaptation of the parasite to the

429 environment across islands. 


\section{Data availability}

432 All raw data generated in this study (raw short sequence reads and draft genome assembly) has

433 been deposited to NCBI, under accession number PRJNAXXX. The final genome assembly and

434 annotation can be found under the accession number GCA_XXX. Supplementary material is

435 available on figshare.

\section{Acknowledgment}

437 We would like to thank Lauren Albert, Taylor Verrett, and Corrine Arthur for field assistance

438 and the Galápagos Science Center and the Galápagos National Park for logistical support. We

439 also thank Noah K. Whiteman for his helpful comments on the manuscript. The sampling was

440 done under Galápagos National Parks permits PC 28-19 and Genetic Access permit MAE-DNB-

441 CM-2016-0041. This project was supported by the Department of Biological Sciences, Kent

442 State University to SL, and the University of Connecticut to SAK.

443

444 Competing interest statement

445 The authors declare no competing interests.

\section{Author contributions}

448 SL and JAHK conceived the idea. SAK, GJV, and JC collected the specimens. CMC and JAHK

449 carried out the laboratory work. MR and SL designed and performed the bioinformatic analyses

450 with the support of CMC and JAHK. SL and JAHK prepared the manuscript, and all authors

451 edited and approved the final version. 


\section{List of Figures}

457 Figure 1: The avian vampire fly, Philornis downsi (a), parasitizes many endemic bird species of 458 the Galapagos Islands, including the medium ground finch, Geospiza fortis (b). The fly is 459 parasitic in its larval forms (c, bottom three) when it feeds on the blood and other fluids of its

460 avian hosts. The larva then pupates (c, second from top) and eclose (c, top) as adult flies.

462 Figure 2: Landscape of Transposable elements in P. downsi (a) Comparison of repeat content

463 and genome size across Diptera and its outgroup (b) Repeat statistics on various classes of

464 transposable elements across dipteran genomes.

Figure 3: Orthogroups in $P$. downsi (a) Phylogenetic relationship between $P$. downsi and other

467 seven published Diptera genomes, estimated using alignments from 3,069 orthogroups had

468 singly copy orthogroups in each species. Horizontal bars for each species show number of

469 orthogroups that are single-copy orthologs in all species, present in all species, present in the

470 majority of species, present in few species, and unique to the species (b) Number of shared

471 orthologs among all species.

473 Figure 4: Gene family evolution (a) Number of genes in Cytochrome P450 gene family across

474 Diptera (b) Number of genes in various subfamilies of Cytochromes P450 gene family in $G$.

475 morsitans and P. downsi, M. domestica and D. melanogaster (c) Number of genes in Glutathione

476 S-transferase gene family across Diptera (d) Number of genes in various subfamilies of 
477 Glutathione S-transferase gene family in G. morsitans and P. downsi, M. domestica and D.

478 melanogaster.

\section{References}

Adams MD, Celniker SE, Holt RA, Evans CA, Gocayne JD, Amanatides PG, et al. (2000). The genome sequence of Drosophila melanogaster. Science 287: 2185-95.

Addesso AM, Harvey JA, Vaziri GJ, Verrett TB, Albert L, Arthur C, et al. (2020). Effect of introduced parasites on the survival and microbiota of nestling cactus finches (Geospiza scandens) in the Galápagos Islands. Journal of Ornithology 161: 1011-1019.

Alves F, Langmore N, Heinsohn R, Stojanovic D (2020). 'Self-fumigation' of nests by an endangered avian host using insecticide-treated feathers increases reproductive success more than tenfold. Animal Conservation.

Bao W, Kojima KK, Kohany O (2015). Repbase Update, a database of repetitive elements in eukaryotic genomes. Mobile DNA 6: 11.

Bourque G, Burns KH, Gehring M, Gorbunova V, Seluanov A, Hammell M, et al. (2018). Ten things you should know about transposable elements. Genome Biol 19: 199-199.

Bulgarella M, Quiroga MA, Boulton RA, Ramirez IE, Moon RD, Causton CE, et al. (2017). Life Cycle and Host Specificity of the Parasitoid Conura annulifera (Hymenoptera: Chalcididae), a Potential Biological Control Agent of Philornis downsi (Diptera: Muscidae) in the Galapagos Islands. Ann Entomol Soc Am 110: 317-328.

Bulgarella M, Quiroga MA, Brito vera GA, Dregni JS, Cunningham F, Mosquera Munoz DA, et al. (2015). Philornis downsi (Diptera: Muscidae), an avian nest parasite invasive to the Galapagos islands, in mainland Ecuador. Annals of the Entomological Society of America.

Bulgarella M, Quiroga MA, Heimpel GE (2019). Additive negative effects of Philornis nest parasitism on small and declining Neotropical bird populations. Bird Conservation International 29: 339-360.

Cantarel BL, Korf I, Robb SMC, Parra G, Ross E, Moore B, et al. (2008). MAKER: an easy-touse annotation pipeline designed for emerging model organism genomes. Genome Res 18: $188-196$.

Causton CE, Cunninghame F, Tapia W (2013). Management of the avian parasite Philornis downsi in the Galapagos Islands: a collaborative and strategic action plan. GNPS, GCREG, CDF, and GC: Puerto Ayora, Galapagos, Ecuador. 
Causton CE, Moon RD, Cimadom A, Boulton RA, Cedeño D, Lincango MP, et al. (2019). Population dynamics of an invasive bird parasite, Philornis downsi (Diptera: Muscidae), in the Galapagos Islands. PLoS One 14: e0224125.

Causton CE, Peck SB, Sinclair BJ, Roque-Albelo L, Hodgson CJ, Landry B (2006). Alien insects: Threats and implications for conservation of Galápagos Islands. Annals of the Entomological Society of America 99: 121-143.

Couri MS, de Carvalho CJB, Lowenberg-Neto P (2007). Phylogeny of Philornis Meinert species (Diptera: Muscidae). Zootaxa: 19-26.

Cunningham F, Achuthan P, Akanni W, Allen J, Amode MR, Armean IM, et al. (2019).

Cunninghame F, Fessl B, Sevilla CR, Young GR, La Greco N (2017). Manejo de la conservacion a largo plazo para salvar al pinzon de manglar (Camarhynchus heliobates) en peligro critico de extincion. DPNG, CGREG, FCD and GC: Puerto Ayora, Galapagos, Ecuador.

De Bie T, Cristianini N, Demuth JP, Hahn MW (2006). CAFE: a computational tool for the study of gene family evolution. Bioinformatics (Oxford, England) 22: 1269-1271.

Dodge HR (1955). New Muscid flies from Florida and the West Indies (Diptera: Muscidae). The Florida Entomologist 38: 147-151.

Dodge HR (1963). A new Philornis with coprophagous larva, and some related species (Diptera: Muscidae). Journal of the Kansas Entomological Society 36: 239-247.

Dudaniec RY, Fessl B, Kleindorfer S (2007). Interannual and interspecific variation in intensity 325-332.

Dudaniec RY, Gardner MG, Donnellan S, Kleindorfer S (2008). Genetic variation in the invasive avian parasite, Philornis downsi (Diptera, Muscidae) on the Galapagos archipelago. BMC Ecology 8: 13.

Dudaniec RY, Kleindorfer S (2006). Effects of the parasitic flies of the genus Philornis (Diptera : Muscidae) on birds. Emu 106: 13-20.

Dvorak M, Vargas H, Fessl B, Tebbich S (2004). On the verge of extinction: a survey of the mangrove finch Cactospiza heliobates and its habitat on the Galápagos Islands. Oryx 38: 1-9.

Emms DM, Kelly S (2015). OrthoFinder: solving fundamental biases in whole genome comparisons dramatically improves orthogroup inference accuracy. Genome Biology 16: 157. 
Fessl B, Heimpel G, Causton C (2018). Invasion of an avian nest parasite, Philornis downsi, to the Galapagos Islands: colonization history, adaptations to novel ecosystems, and conservation challenges. In: Parker P (ed) Disease Ecology, Social and Ecological Interactions in the Galapagos Islands, Springer International Publishing.

Fessl B, Sinclair BJ, Kleindorfer S (2006). The life-cycle of Philornis downsi (Diptera : Muscidae) parasitizing Darwin's finches and its impacts on nestling survival. Parasitology 133: 739-747.

Fessl B, Tebbich S (2002). Philornis downsi - a recently discovered parasite on the Galápagos archipelago - a threat for Darwin's finches? Ibis 144: 445-451.

Fessl B, Young GH, Young RP, Rodríguez-Matamoros J, Dvorak M, Tebbich S, et al. (2010). How to save the rarest Darwin's finch from extinction: the mangrove finch on Isabela Island. Philos Trans R Soc Lond B Biol Sci 365: 1019-1030.

Festucci-Buselli RA, Carvalho-Dias AS, de Oliveira-Andrade M, Caixeta-Nunes C, Li HM, Stuart JJ, et al. (2005). Expression of Cyp6g1 and Cyp12d1 in DDT resistant and susceptible strains of Drosophila melanogaster. Insect Mol Biol 14: 69-77.

Feyereisen R (2012). Insect CYP genes and P450 enzymes. In: Gilbert LI, editor. Insect Molecular Biology and Biochemistry: 236-316.

Flynn JM, Hubley R, Goubert C, Rosen J, Clark AG, Feschotte C, et al. (2019). RepeatModeler2: automated genomic discovery of transposable element families. bioRxiv: 856591.

Gibbs GM, Roelants K, O'Bryan MK (2008). The CAP Superfamily: Cysteine-Rich Secretory Proteins, Antigen 5, and Pathogenesis-Related 1 Proteins-Roles in Reproduction, Cancer, and Immune Defense. Endocrine Reviews 29: 865-897.

Grant PR, Grant BR, Petren K, Keller LF (2005). Extinction behind our backs: the possible fate of one of the Darwin's finch species on Isla Floreana, Galápagos. Biological Conservation 122: 499-503.

Hanington PC, Zhang S-M (2011). The primary role of fibrinogen-related proteins in invertebrates is defense, not coagulation. J Innate Immun 3: 17-27.

Heimpel GE, Hillstrom A, Freund D, Knutie SA, Clayton DH (2017). Invasive Parasites and the Fate of Darwin's Finches in the Galapagos Islands: The Case of the Vegetarian Finch (Platyspiza crassirostris). Wilson J Ornithol 129: 345-349.

Hu J, Zhang JL, Nardi F, Zhang RJ (2008). Population genetic structure of the melon fly, Bactrocera cucurbitae (Diptera: Tephritidae), from China and Southeast Asia. Genetica 134: 319-24.

Iga M, Kataoka H (2012). Recent Studies on Insect Hormone Metabolic Pathways Mediated by Cytochrome P450 Enzymes. Biological and Pharmaceutical Bulletin 35: 838-843. 
Kapusta A, Suh A, Feschotte C (2017). Dynamics of genome size evolution in birds and mammals. Proceedings of the National Academy of Sciences 114: E1460 LP-E1469.

Ketterman AJ, Saisawang C, Wongsantichon J (2011). Insect glutathione transferases. Drug Metabolism Reviews 43: 253-265.

Kidwell MG (2002). Transposable elements and the evolution of genome size in eukaryotes. Genetica 115: 49-63.

Knutie SA, McNew SM, Bartlow AW, Vargas DA, Clayton DH (2014). Darwin's finches combat introduced nest parasites with fumigated cotton. Current Biology 24: R355R356.

Knutie SA, Owen JP, McNew SM, Bartlow AW, Arriero E, Herman JM, et al. (2016a). Galapagos mockingbirds tolerate introduced parasites that affect Darwin's finches. Ecology 97: 940-950.

Koop JAH, Causton CE, Bulgarella M, Cooper E, Heimpel GE (2021). Population structure of a nest parasite of Darwin's finches within its native and invasive ranges. Conservation Genetics 22: 11-22.

Koop JAH, Huber SK, Laverty SM, Clayton DH (2011). Experimental demonstration of the

Koop JAH, Kim PS, Knutie SA, Adler F, Clayton DH (2015). Introduced parasitic fly may lead doi:10.1371/journal.pone.0019706.

Koop JAH, Le Bohec C, Clayton DH (2013). Dry year does not reduce invasive parasitic fly

Koop JAH, Owen JP, Knutie SA, Aguilar MA, Clayton DH (2013). Experimental demonstration of a parasite-induced response in wild birds: Darwin's finches and introduced nest flies. Ecology and Evolution 3: 2514-2523.

\section{Lamichhaney S, Catullo R, Keogh JS, Clulow S, Edwards SV, Ezaz T (2021). A bird-like} genome from a frog: Mechanisms of genome size reduction in the ornate burrowing frog, Platyplectrum ornatum. Proceedings of the National Academy of Sciences 118: e2011649118.

613 McNew SM, Knutie SA, Clayton DH (2020). No evidence of sex ratio manipulation by 614 Galápagos mockingbirds in response to environment. Journal of Avian Biology 51. 
Mi H, Ebert D, Muruganujan A, Mills C, Albou L-P, Mushayamaha T, et al. (2021). PANTHER version 16: a revised family classification, tree-based classification tool, enhancer regions and extensive API. Nucleic Acids Research 49: 394-403.

O'Connor JA, Robertson J, Kleindorfer S (2014). Darwin's finch begging intensity does not honestly signal need in parasitised nests. Ethology 120: 228-237.

Olafson PU, Aksoy S, Attardo GM, Buckmeier G, Chen X, Coates CJ, et al. (2021). The genome of the stable fly, Stomoxys calcitrans, reveals potential mechanisms underlying reproduction, host interactions, and novel targets for pest control. BMC Biology 19: 41.

Peters KJ, Kleindorfer S (2018). Avian population trends in Scalesia forest on Floreana Island (2004-2013): Acoustical surveys cannot detect hybrids of Darwin's tree finches Camarhynchus spp. Bird Conservation International 28: 319-335.

Petersen M, Armisén D, Gibbs RA, Hering L, Khila A, Mayer G, et al. (2019). Diversity and evolution of the transposable element repertoire in arthropods with particular reference to insects. BMC Evol Biol 19: 11-11.

Pourrajab F, Hekmatimoghaddam S (2021). Transposable elements, contributors in the evolution of organisms (from an arms race to a source of raw materials). Heliyon 7: e06029e06029.

Ranallo-Benavidez TR, Jaron KS, Schatz MC (2020). GenomeScope 2.0 and Smudgeplot for reference-free profiling of polyploid genomes. Nature Communications 11: 1432.

Schrader L, Kim JW, Ence D, Zimin A, Klein A, Wyschetzki K, et al. (2014). Transposable element islands facilitate adaptation to novel environments in an invasive species. Nature Communications 5: 5495.

Scott JG (1999). Cytochromes P450 and insecticide resistance. Insect Biochem Mol Biol 29: 757-77.

Scott MJ, Benoit JB, Davis RJ, Bailey ST, Varga V, Martinson EO, et al. (2020). Genomic analyses of a livestock pest, the New World screwworm, find potential targets for genetic control programs. Communications Biology 3: 424-424.

Scott JG, Warren Wc Fau - Beukeboom LW, Beukeboom Lw Fau - Bopp D, Bopp D Fau - Clark AG, Clark Ag Fau - Giers SD, Giers Sd Fau - Hediger M, et al. (2014). Genome of the house fly, Musca domestica L., a global vector of diseases with adaptations to a septic environment.

Smit Hubley P. AFA R\& Green (2013). RepeatMasker Open-4.0,.

Spalding MG, Mertins JW, Walsh PB, Morin KC, Dunmore DE, Forrester DJ (2002). Burrowing fly larvae (Philornis porteri) associated with mortality of eastern bluebirds in Florida. Journal of Wildlife Diseases 38: 776-783. 
Vurture GW, Sedlazeck FJ, Nattestad M, Underwood CJ, Fang H, Gurtowski J, et al. (2017). 2202-2204.

653 Waterhouse RM, Seppey M, Simao FA, Manni M, Ioannidis P, Klioutchnikov G, et al. (2017). BUSCO applications from quality assessments to gene prediction and phylogenomics. Molecular biology and evolution.

Weisel JW, Litvinov RI (2017). Fibrin Formation, Structure and Properties. Subcell Biochem 82: 405-456.

Weisenfeld NI, Kumar V, Shah P, Church DM, Jaffe DB (2017). Direct determination of diploid genome sequences. Genome Research 27: 757-767.

Wen Z, Zhang X, Zhang Y (2011). P450 - mediated Insecticide Detoxification and Its Implication in Insecticide Efficacy. In: Liu T, Kang L (eds) Recent Advances in Entomological Research: From Molecular Biology to Pest Management, Springer Berlin Heidelberg: Berlin, Heidelberg, pp 229-245.

Zheng GXY, Lau BT, Schnall-Levin M, Jarosz M, Bell JM, Hindson CM, et al. (2016). Haplotyping germline and cancer genomes with high-throughput linked-read sequencing. Nature Biotechnology 34: 303-311. permethrin exposure in permethrin resistant house flies, Musca domestica. BMC Physiol 8: 18 . 
a

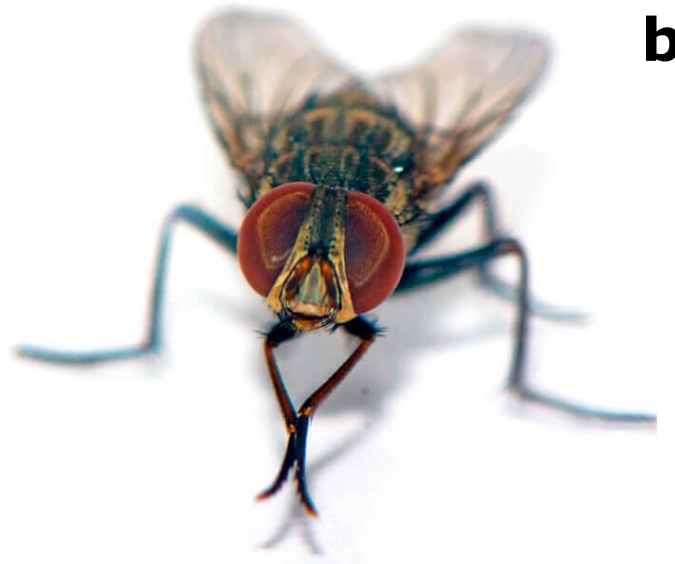

C
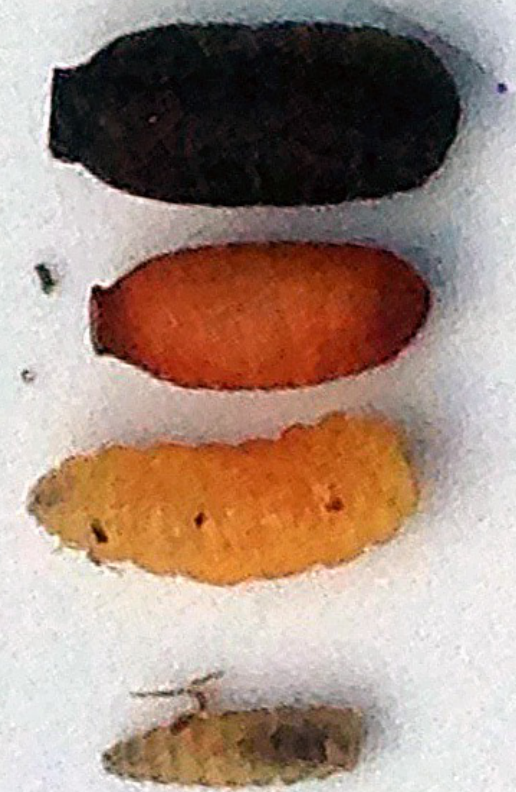

$$
\text { C. }
$$

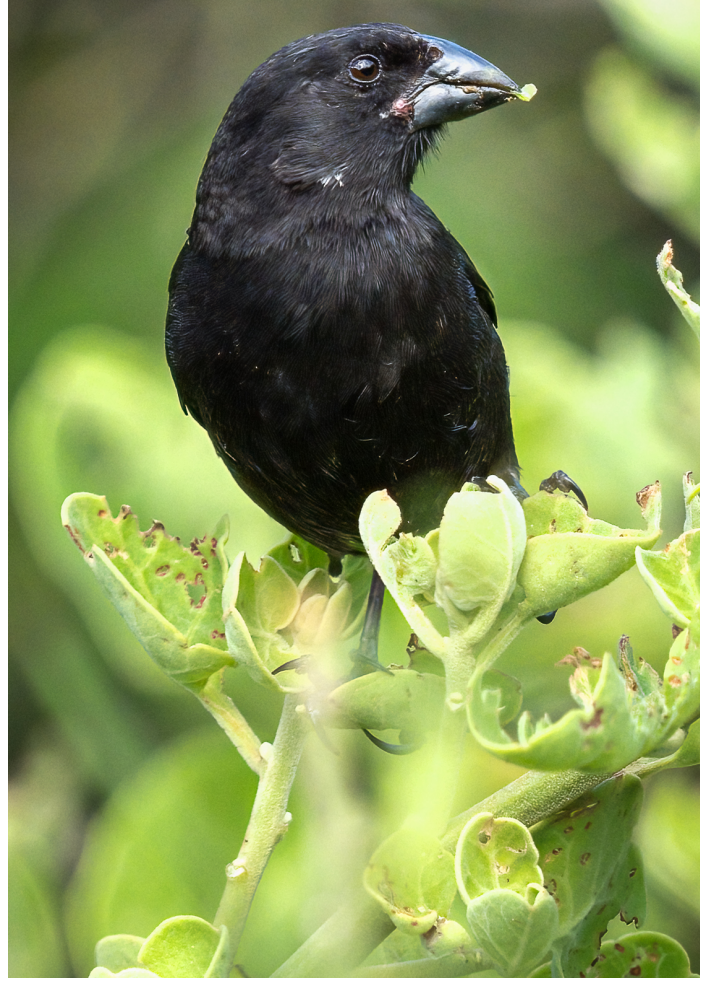

Figure 1 
bipRxiy preprint doi: https://doi.org/10.1101/2021.06.09.447800; this version posted June 12, 2021. The copyright holder for this preprint (which was not certified by peer review) is the author/funder. All rights reserved. No reuse allowed without paremiesion.

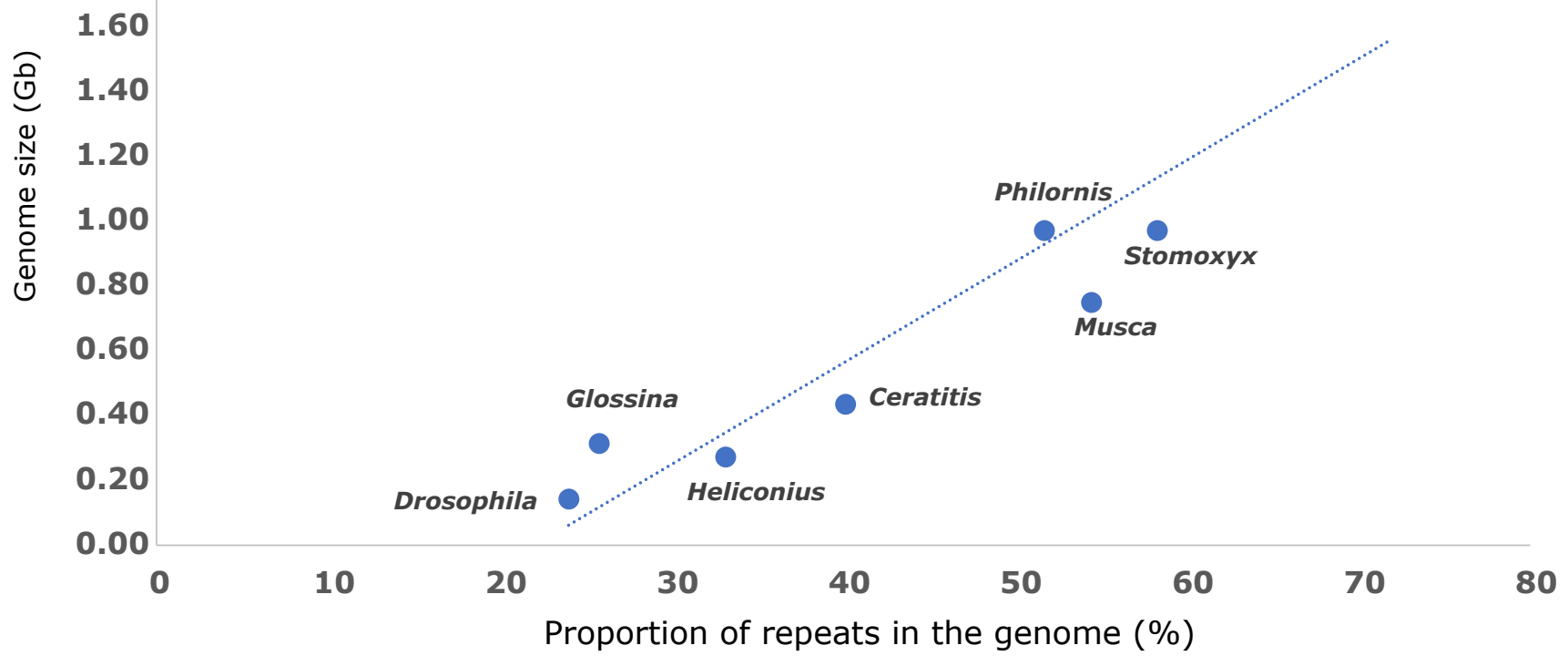

b

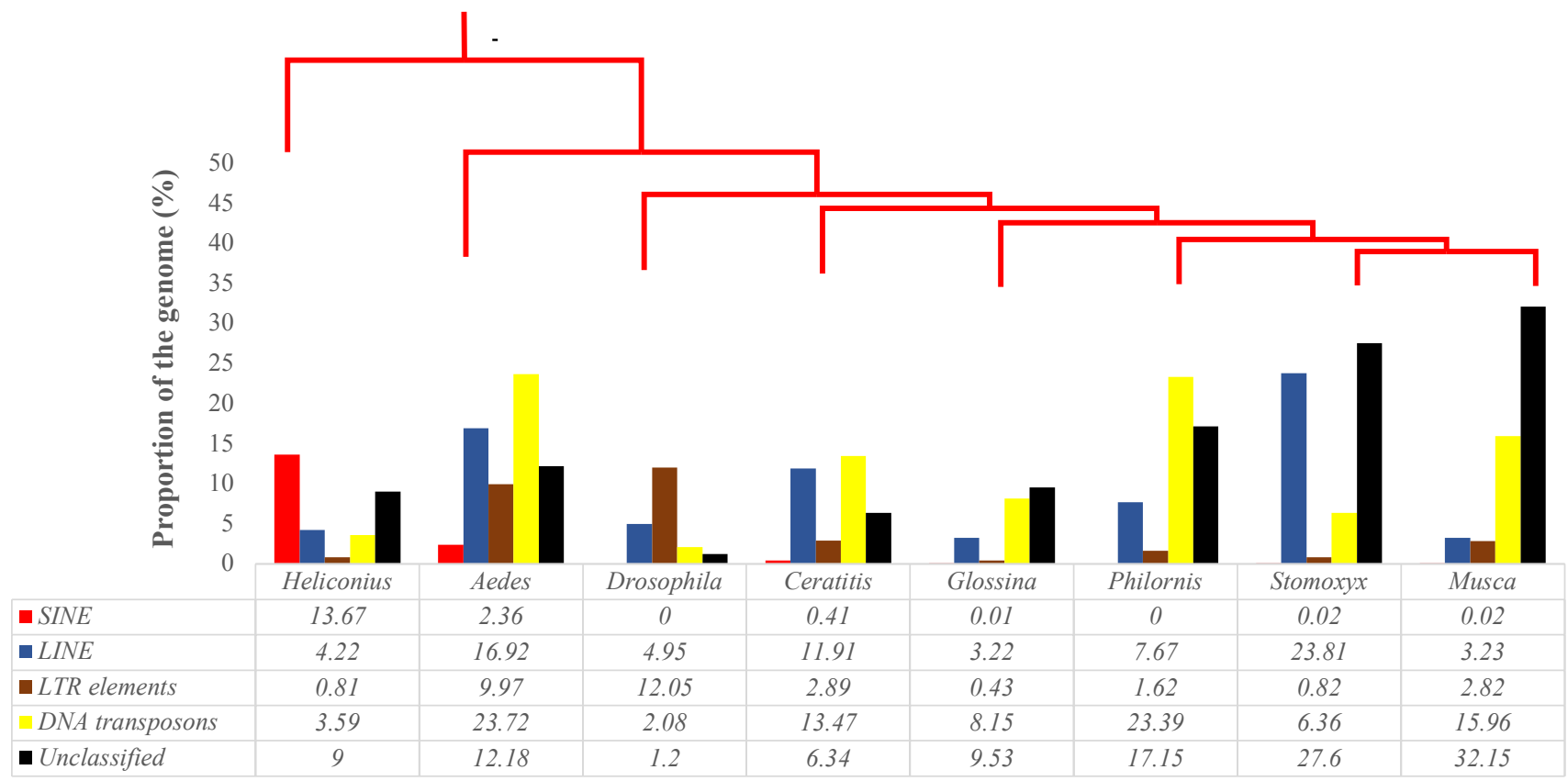

Figure 2 


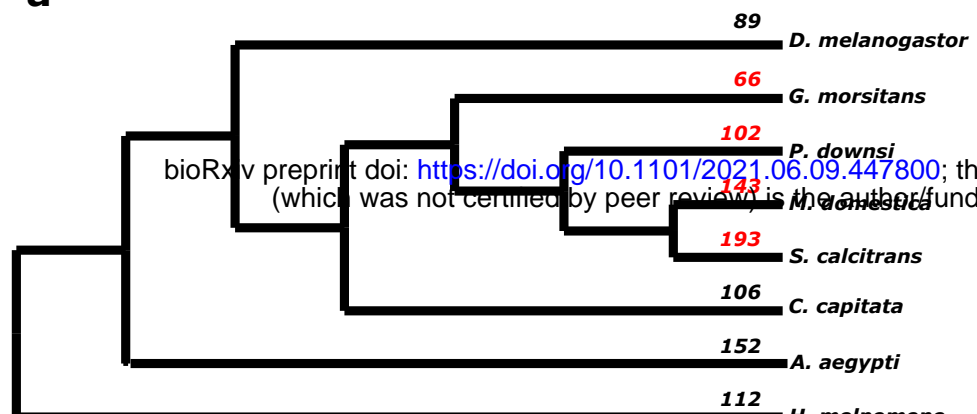

112

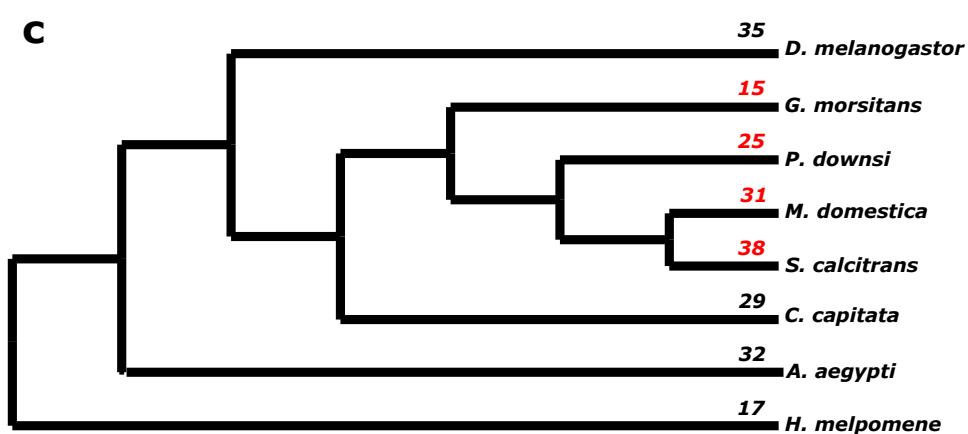

40

\&ersion posted June 12,2021 . The copyright holde

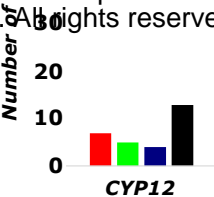

CYP12

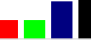

CYP28

CYP4

CYP6

W

CYP9

others

d

D. melanogastor

G. morsitans

P. downsi

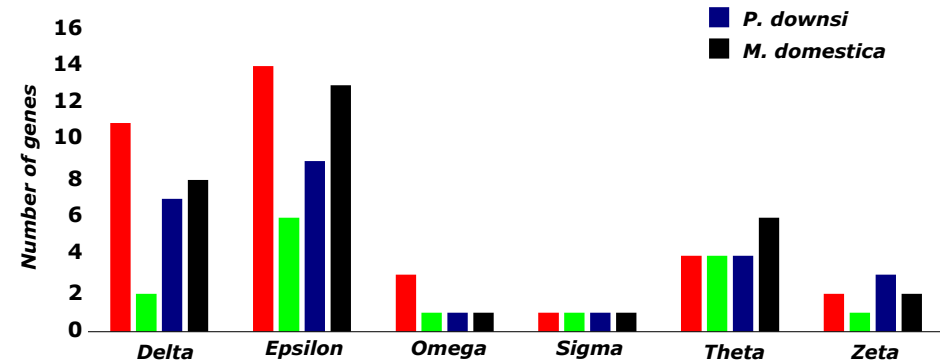

Figure 4 
9 Property

10 Heterozygosity

11 Genome Haploid Length

12 Genome Repeat Length

13 Genome Unique Length

14 Model Fit

15 Read Error Rate

\section{Supplementary Materials}

The genome sequence of the avian vampire fly (Philornis downsi), an invasive nest parasite of Darwin's finches

18 Supplementary Table 2: Repeat statistics in P. downsi genome

19 sequences: $\quad 41,176$

20 total length: $971,6346,46 \mathrm{bp}$

21 GC level: $\quad 35.10 \%$

22 bases masked: 502,200,627 bp (51.69\%)

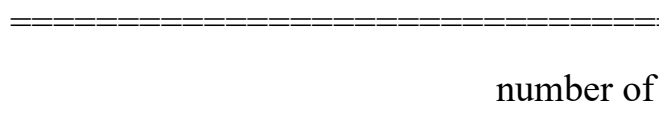

$\min$

$1.40879 \%$

$796,797,589$ bp

$232,405,721 \mathrm{bp}$

$564,391,869$ bp

$95.7713 \%$

$1.228 \%$

elements*

224657

58

3187

196268

0

43733

15852

834

102395 length

occupied

90253146 bp

6761 bp

661022 bp

74550945 bp

$0 \mathrm{bp}$

$18550153 \mathrm{bp}$

7502835 bp

673762 bp

29493616 bp $\max$

$1.42194 \%$ $799,050,413$ bp 233,062,812 bp $565,987,600$ bp $98.7012 \%$ $1.228 \%$

RTE/Bov-B

102395




\section{L1/CIN4}

LTR elements:

Rolling-circles

Unclassified:

Total interspersed repeats:

Small RNA:

Satellites:

Simple repeats:

Low complexity:
19653

7148

796

\section{5}

28331

12565

1561

9951

2481

621139

8749

576750

0

0

1280

4060

275

828801

213281

34278

$\begin{array}{ll}94740 \text { bp } & 0.01 \% \\ \mathbf{1 5 6 9 5 4 4 0} \text { bp } & \mathbf{1 . 6 2} \% \\ 7084057 \text { bp } & 0.73 \% \\ 775084 \text { bp } & 0.08 \% \\ 7481940 \text { bp } & 0.77 \% \\ 143387 \text { bp } & 0.01 \%\end{array}$

227262774 bp $\quad 23.39 \%$

$1542960 \mathrm{bp} \quad 0.16 \%$

$212960682 \mathrm{bp} \quad 21.92 \%$

$0 \mathrm{bp}$

$0.00 \%$

$0 \mathrm{bp}$

$0.00 \%$

$395680 \mathrm{bp}$

$0.04 \%$

1924044 bp

$0.20 \%$

$11451 \mathrm{bp}$

$0.00 \%$

\section{9 bp $\quad 17.14 \%$}

484024259 bp $\quad 49.82 \%$

2907047 bp $\quad 0.30 \%$

$124775 \mathrm{bp} \quad 0.01 \%$

$8909635 \mathrm{bp} \quad 0.92 \%$

69 
Supplementary Table 4: Gene families unique only to P. downsi

\begin{tabular}{|l|l|}
\hline EGT47331 & hypothetical protein CAEBREN_08836 [Caenorhabditis brenneri] \\
\hline GBO13109 & hypothetical protein AVEN_233885-1 [Araneus ventricosus] \\
\hline GBP44057 & PiggyBac transposable element-derived protein 4 [Eumeta japonica] \\
\hline KMQ83311 & transposable element tc3 transposase [Lasius niger] \\
\hline KNC20639 & hypothetical protein FF38_06891, partial [Lucilia cuprina] \\
\hline KNC20966 & hypothetical protein FF38_09018 [Lucilia cuprina] \\
\hline KNC26906 & hypothetical protein FF38_10930 [Lucilia cuprina] \\
\hline KXJ68891 & hypothetical protein RP20_CCG001210 [Aedes albopictus] \\
\hline OAF68034 & hypothetical protein A3Q56_04227 [Intoshia linei] \\
\hline PCG68510 & hypothetical protein B5V51_5157, partial [Heliothis virescens] \\
\hline XP_011295145 & $\begin{array}{l}\text { PREDICTED: tigger transposable element-derived protein 6-like isoform X2 [Musca } \\
\text { domestica] }\end{array}$ \\
\hline XP_011295374 & PREDICTED: tigger transposable element-derived protein 6 [Musca domestica] \\
\hline XP_013109704 & PREDICTED: uncharacterized protein LOC106088638 [Stomoxys calcitrans] \\
\hline XP_017475229 & PREDICTED: uncharacterized protein LOC108365650 [Rhagoletis zephyria] \\
\hline XP_017478109 & PREDICTED: uncharacterized protein LOC108367917 [Rhagoletis zephyria] \\
\hline XP_017478991 & PREDICTED: uncharacterized protein LOC108368617 [Rhagoletis zephyria] \\
\hline XP_017479715 & PREDICTED: uncharacterized protein LOC108369194 [Rhagoletis zephyria] \\
\hline XP_017481195 & $\begin{array}{l}\text { PREDICTED: RNA-directed DNA polymerase from mobile element jockey-like } \\
\text { [Rhagoletis zephyria] }\end{array}$ \\
\hline XP_019891578 & PREDICTED: ATP-binding cassette sub-family A member 3-like [Musca domestica] \\
\hline XP_019894716 & PREDICTED: uncharacterized protein LOC105262305 isoform X1 [Musca domestica] \\
\hline XP_021704105 & protein ALP1-like [Aedes aegypti] \\
\hline XP_022823959 & piggyBac transposable element-derived protein 4-like [Spodoptera litura] \\
\hline XP_022834134 & uncharacterized protein LOC111361914 [Spodoptera litura] \\
\hline XP_033325321 & uncharacterized protein LOC117219890 [Megalopta genalis] \\
\hline XP_036214104 & trypsin zeta-like [Bactrocera oleae] \\
\hline XP_036337749 & uncharacterized protein LOC118747737 isoform X3 [Rhagoletis pomonella] \\
\hline XP_036342696 & uncharacterized protein LOC118751975 [Rhagoletis pomonella] \\
\hline & \\
\hline
\end{tabular}

74

75

76

77

Supplementary Table 5: Number of genes in Fibrinogen C-Terminal Domain-Containing gene family and SCP domain-containing gene family

\begin{tabular}{|l|r|r|r|}
\hline Species & $\begin{array}{l}\text { Fibrinogen C-Terminal Domain- } \\
\text { Containing gene family }\end{array}$ & 1 & SCP domain-containing gene family \\
\hline H.melpomene & 33 & 2 \\
\hline A.aegypti & 10 & 6 \\
\hline C.capitata & 45 & 17 \\
\hline S.calcitrans & 32 & 5 & 25 \\
\hline M.domestica & 7 & 7 \\
\hline P.downsi & 11 & 7 \\
\hline G.morsitans & & 15 \\
\hline D.melanogaster & & & 6 \\
\hline
\end{tabular}




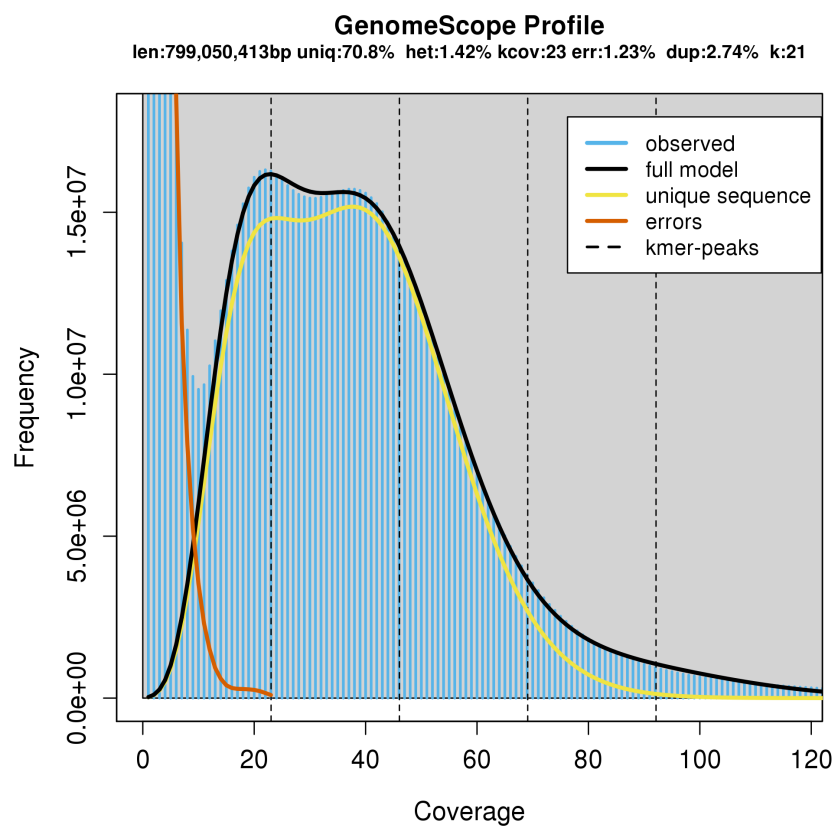

80 Supplementary Figure 1: $k$-mer spectrum and fitted modelling used for estimating genome parameters 81 of $P$. downsi from short sequencing reads

82

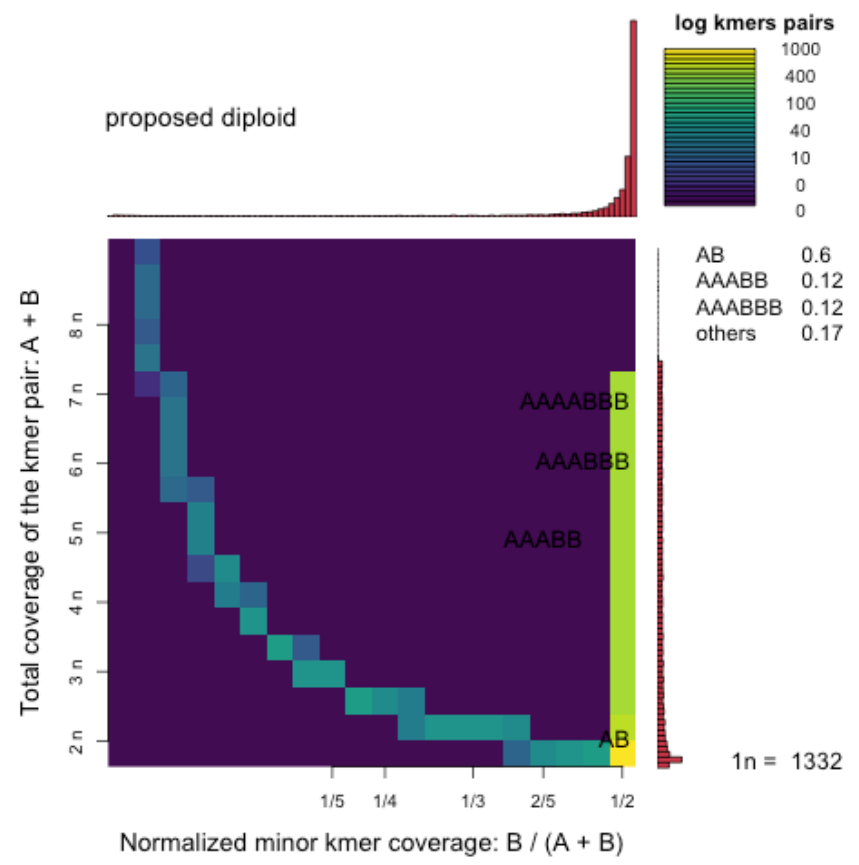

84 Supplementary Figure 2: Distribution of the total coverage of the k-mer pair (y-axis) against relative 85 minor k-mer coverage (x-axis) providing evidence of diploidy in P. downsi. 


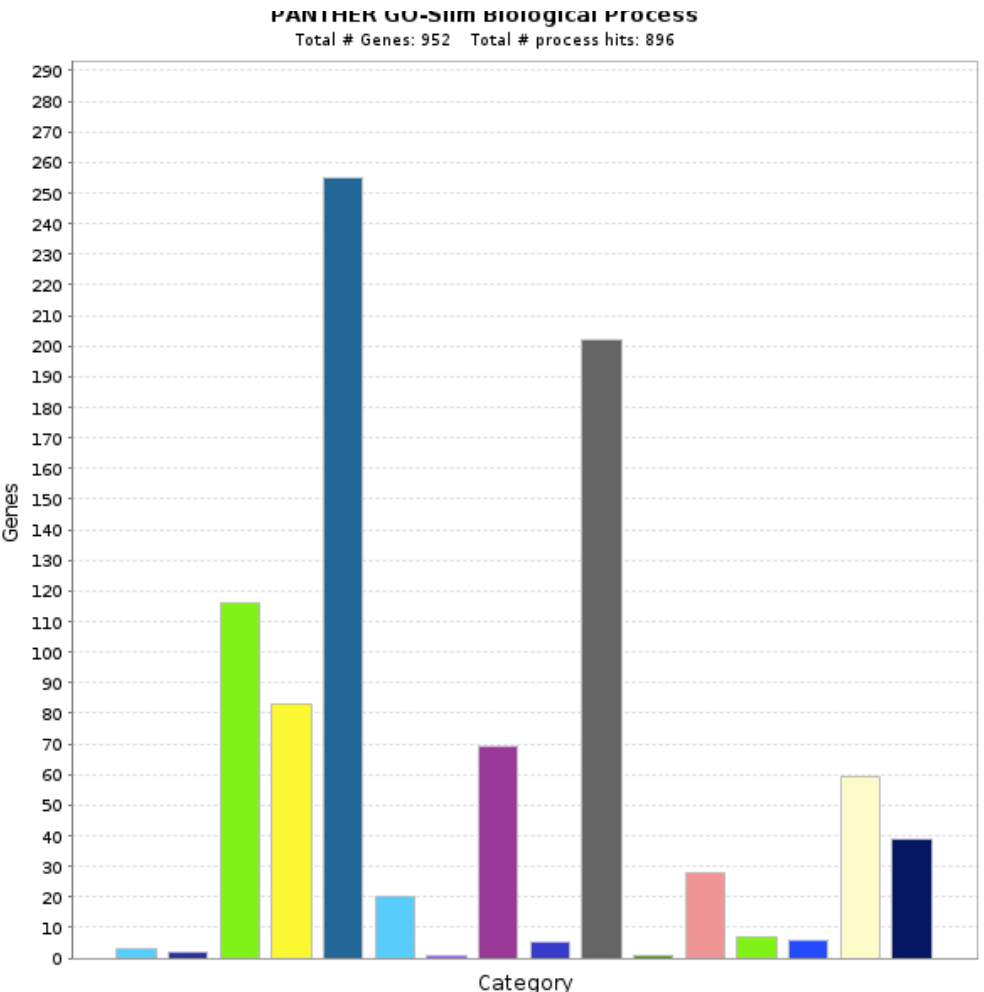

Click to get gene list for a category:

biological adhesion (GO:0022610)

- biological phase (GO:0044848).

biological regulation (GO:0065007).

cellular component organization or biogenesis (GO:0071840).

- cellular process (GO:0009987).

developmental process (GO:0032502).

- immune system process (GO:0002376).

- localization (GO:0051179).

- locomotion (GO:0040011).

- metabolic process (GO:0008152).

multi-organism process (GO:0051704).

multicellular organismal process (GO:0032501).

reproduction (GO:0000003).

- reproductive process (GO:0022414).

response to stimulus (GO:0050896)

- signaling_(GO:0023052).

Color picker powered by $\approx \begin{aligned} & \text { Web } \\ & \text { Colors by } \\ & \text { VisiBone }\end{aligned}$

89 Supplementary Figure 3: Gene ontology terms associated with 993 gene families unique to diptera

90

91

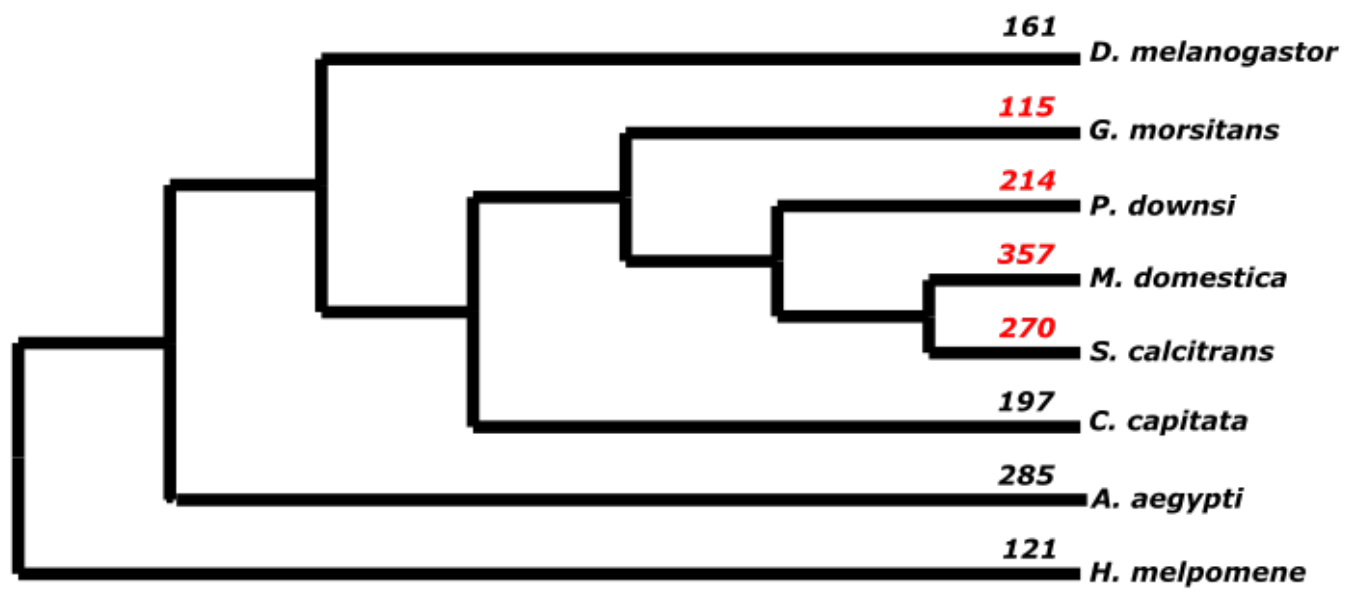

94 Supplementary Figure 4: Number of genes in Cuticular gene family across dipterans 